\title{
Review Article \\ Stem Cells for Bone Regeneration: From Cell-Based Therapies to Decellularised Engineered Extracellular Matrices
}

\author{
James N. Fisher, ${ }^{1}$ Giuseppe M. Peretti, ${ }^{1,2}$ and Celeste Scotti ${ }^{1}$ \\ ${ }^{1}$ IRCCS Istituto Ortopedico Galeazzi, 20161 Milan, Italy \\ ${ }^{2}$ Dipartimento di Scienze Biomediche per la Salute, Università degli Studi di Milano, 20122 Milan, Italy \\ Correspondence should be addressed to Celeste Scotti; celestescotti@hotmail.com
}

Received 10 September 2015; Revised 11 January 2016; Accepted 17 January 2016

Academic Editor: Li Jin

Copyright (c) 2016 James N. Fisher et al. This is an open access article distributed under the Creative Commons Attribution License, which permits unrestricted use, distribution, and reproduction in any medium, provided the original work is properly cited.

\begin{abstract}
Currently, autologous bone grafting represents the clinical gold standard in orthopaedic surgery. In certain cases, however, alternative techniques are required. The clinical utility of stem and stromal cells has been demonstrated for the repair and regeneration of craniomaxillofacial and long bone defects although clinical adoption of bone tissue engineering protocols has been very limited. Initial tissue engineering studies focused on the bone marrow as a source of cells for bone regeneration, and while a number of promising results continue to emerge, limitations to this technique have prompted the exploration of alternative cell sources, including adipose and muscle tissue. In this review paper we discuss the advantages and disadvantages of cell sources with a focus on adipose tissue and the bone marrow. Additionally, we highlight the relatively recent paradigm of developmental engineering, which promotes the recapitulation of naturally occurring developmental processes to allow the implant to optimally respond to endogenous cues. Finally we examine efforts to apply lessons from studies into different cell sources and developmental approaches to stimulate bone growth by use of decellularised hypertrophic cartilage templates.
\end{abstract}

\section{Introduction}

Bone tissue is capable of spontaneous self-repair, with no scarring, generating new tissue that is all but indistinguishable from surrounding bone. However, in certain circumstances, the defect is too large (due to tumour resection, osteomyelitis, atrophic nonunions, and periprosthetic bone loss), or the underlying physiological state of the patient impairs natural healing (osteoporosis, infection, diabetes, and smoking) necessitating intervention. Autologous bone grafting is today the gold standard for bone repair, although the costs of this approach are considerable due to the additional surgical procedures required to harvest the bone material, the consequent donor site morbidity [1], and the risk of infection and complications. Additionally, this approach is hampered by the limited amount of donor material available for transplantation which can be prohibitive when dealing with large defects. To resolve these issues, both allograft- and xenograft-based strategies have been proposed; however the risk of rejection in the former and of zoonoses in the latter has reduced their clinical impact. Bone tissue engineering (BTE) is an alternative strategy that has been explored to fill the clinical need for autologous bone transplantation.

Almost half a century has passed since the demonstration that ectopic transplantation of bone marrow and bone fragments leads to the formation of de novo bone tissue which, when transplanted subcutaneously, is later filled with bone marrow $[2,3]$. Nowadays, the notion that a set of cells present in the bone marrow stroma can be cultured in vitro and can regenerate fully functional bone organs in vivo is well accepted, although the identity and precise molecular characterisation of the cell population responsible are still a matter of study and debate (reviewed in $[4,5]$ ). The ex vivo expansion and manipulation of stromal cells derived from various sources form the foundation of the majority of current bone tissue engineering attempts to meet the clinical demands for bone regeneration and repair.

Over the last 50 years, the BTE field has made significant advances towards overcoming the limitations of conventional methods which is particularly relevant when an underlying 
pathology calls for alternatives to the status quo. Clinically, several examples of successful application of tissue engineering techniques to bone reconstruction exist within the literature [6-8]; however, on the whole, advances in basic science have not translated well into significantly increased clinical application. The reasons are, in part, financial, but additional problems such as low efficiency of differentiation, intrapatient variability [9], the risk of ectopic bone growth [10], possible transformation [11], or epithelial to mesenchymal transition coupled with an incomplete understanding of the underlying pathways which are being manipulated with factors, such as transforming growth factor $\beta$ (TGF- $\beta$ ) and bone morphogenic proteins (BMPs) $[10,12-15]$, certainly play a role.

Minimal clinical adoption has prompted the exploration and adaptation of alternative methods including the use of stromal cells from nonbone sources [16, 17], most commonly, adipose tissue [8, 18-20], but also muscle [17]; the development of new tissue engineering paradigms in which the focus is shifted from "cells + cytokines" to the engineering and in vitro optimisation of treatments as a means to support in vivo developmental processes by harnessing innate developmental pathways [21-26]; and finally, attempts to create "off-theshelf" products to stimulate the regeneration of bone through adoption of developmental engineering principles [27-29]. The various merits of these points will be the focus of this review.

\section{Cell Source}

While the bone marrow (BM) represents the most welldocumented source of cells for the regeneration and repair of skeletal tissues, a wide variety of alternatives, including adipose tissue (AT) [18, 19], muscle [17], umbilical cord blood $[16,30]$, umbilical cord Wharton's jelly [31], dental pulp [32], and periosteal tissue [33], have been explored for bone regeneration. For the purpose of this review, we will focus on two sources of stromal cells which have been the subject of the greatest number of studies in recent years and which are both attractive for different reasons, namely, the bone marrow and adipose tissue.

2.1. From Bone Fragment Transplants to Identification of the Skeletal Stem Cell. In the late 1960s it was shown that bone fragments and/or suspensions of cultured bone marrow cells, when ectopically implanted in mice, rats, rabbits, and guineapigs, were capable of forming bone composed of donor osteoblasts, osteocytes, and bone marrow stroma adipocytes, which was capable of attracting host haematopoietic cells to the bone marrow stroma $[3,34]$. It was later shown that, by plating cultured, nonhaematopoietic, bone marrow suspensions at low density, a specific subpopulation of plasticadherent fibroblast-like cells could be isolated that were responsible for single-cell colony formation, the colonyforming unit-fibroblast (CFU-f) $[35,36]$. It was clear that a nonhaematopoietic cell population within the bone marrow was responsible for the in vivo regeneration and spatial organisation of skeletal tissues.
In the early 1990s Arnold Caplan's group showed that rat bone marrow-derived mesenchymal cells, purified through plastic adherence, could be passaged multiple times, demonstrating self-renewal (albeit in vitro), and were still capable of differentiation into cells of the skeletal system in vivo, namely, osteoblasts and chondrocytes, and coined the term "mesenchymal stem cell" [37, 38]. Further studies in humans confirmed the ability of a rapidly dividing subset of bone marrow-derived stromal cells (BMSCs) to differentiate into skeletal lineages (bone, cartilage, adipocytes, and marrow stroma) $[39,40]$ in a hierarchical manner and to undergo in vitro self-renewal, giving rise to secondary colonies upon replating at the clonal level [41, 42].

In vivo demonstration of BMSC stem cell characteristics, namely, self-replication and multipotency, came with the description of CD146+/MCAM (melanoma cell adhesion molecule) [43] and nestin ${ }^{+}$[44] perivascular adventitial cells. Transplantation of single CFU-f-derived CD146 ${ }^{+}$ colonies implanted in hydroxyapatite-tricalcium phosphate (HA-TCP) carrier in a fibrin gel in mice resulted in the formation of ossicles with a functional bone marrow populated by murine (host) haematopoietic cells and endothelium with human $\mathrm{CD}_{146^{+}}$adventitial cells lining the sinusoidal vessels, which were capable of generating secondary CFUfs in vitro [43]. Similarly, implantation of nestin ${ }^{+}$clonal cell spheres harvested two months after subcutaneous implantation in mice resulted in the generation of secondary ossicles with donor-derived osteoblasts and nestin ${ }^{+}$cells after eight months [44]. Nestin ${ }^{+}$cells were shown to spatially associate with haematopoietic stem cells (HSCs), to express high levels of HSC maintenance genes, and to influence HSC homing in addition to differentiation into osteochondral lineages; in addition they were shown to be entirely responsible for the clonogenic activity of the $\mathrm{CD}^{-} 5^{-}$cell fraction [44]. More recently, evidence for a skeletal stem cell (SSC) resident in the BM reticulum, characterised by expression of the BMP antagonist Gremlin-1, has emerged [45] which has challenged previous ideas about the identity of the SSC, particularly the use of nestin as an appropriate SSC marker and the developmental origins of BM adipocytes [45], although it is possible that these conflicting data may be due to different active populations of SSCs during different phases of development $[45,46]$.

2.2. Clinical BTE Application of BMSCs. Practically, BMSCs are applicable to large bone defects in both small [47] and large $[48,49]$ animals when implanted within hydroxyapatite-based scaffolds. Experimental evidence for the ability of BMSCs to repair bone defects was given crucial clinical support in 2001, when Quarto and colleagues published results obtained in three patients with various long bone defects [6]. BMSCs were isolated and expanded ex vivo under the stimulation of specific growth factors [50] before implantation on hydroxyapatite (HA) scaffolds tailored to the dimensions of each bone defect. It was reported that "all patients recovered limb function" and that, within two months of implantation, good integration with the recipient 
bone was observed [6]. Shortly afterwards, the use of autologous BM encased within a titanium cage with bone mineral blocks for reconstructive mandibular reconstruction was reported [51]. The scaffold was implanted in the dorsal latissimus dorsi muscle for seven weeks allowing for growth and vascularisation before transplantation of the bone-muscle flap. This method, while slow, avoided the creation of a donor site bone defect. More recently, the successful treatment of long bone defects in four patients was reported after 6-7 years of follow-up [52]. As of the time of writing, 33 clinical trials (https://www.clinicaltrials.gov/) are registered for the use of BMSCs, only two of which are directed towards bone repair or regeneration: NCT02177565 is investigating the use of in vitro expanded autologous BMSCs for the treatment of nonunions although at the time of writing the trial has been completed, but no results are posted. The multicentre ORTHO-2 trial for the "Evaluation of Mesenchymal Stem Cells to Treat Avascular Necrosis of the Hip" (NCT02065167), as part of the REBORNE (regenerating bone defects using new biomedical engineering approaches) programme, for the use of autologous BMSCs for the treatment of necrosis of the femoral head got underway in late 2014; however no results are available as of yet. The paucity of clinical trials investigating the potential of autologous BMSCs for bone repair and regeneration likely reflect hurdles to clinical use, be it GMP cell expansion, interpatient variability, or the difficulty in enrolling sufficient patients, notwithstanding positive results previously reported [6].

2.3. Bone from Fat: Successful Application of Fat-Derived Cells for BTE. Concurrent with studies illustrating the clinical application of BMSCs for bone regeneration, it was demonstrated that human processed lipoaspirate (PLA) cells, isolated from liposuction procedures, could be induced to differentiate into osteogenic, adipogenic, chondrogenic, and myogenic lineages through incubation in specific media [18] and showed increased expression of core-binding factor alpha1 (CBFA-1)/runt-related transcription factor 2 (RUNX2), osteocalcin, and alkaline phosphatase, following induction in osteogenic medium [19]. These results were paralleled by a 30 -fold increase in matrix calcification suggesting the applicability of adipose tissue-derived stromal cells (ADSCs) to bone repair. Multiple studies into the BTE potential of ADSCs were published in the following years both in vitro $[16,53,54]$ and in vivo in animal models [20,55-58] and in humans $[7,8,59]$. Many studies noted not only the greater accessibility of ADSCs, but also the greater number of progenitors in lipoaspirates (100 times the number of progenitors compared to the same volume of BM) [60]. Animal studies not only revealed the potential of ADSCs to generate functional bone $[16,20,56,61]$ but also demonstrated additional advantages over bone marrow derived counterparts, such as a propensity for greater proliferation [62] and CFU-f formation [16, 58], reduced senescence in vitro $[16,54]$, and greater production of CXCL 12 [57], the so-called HSC-niche factor [63], and lower risk of malignant transformation [11].

The clinical application of ADSCs for BTE is followed rapidly with a case report of maxillary reconstruction. GMPexpanded ADSCs were induced with BMP-2, seeded onto a beta-tricalcium phosphate $(\beta$-TCP) scaffold, and implanted within the patient's rectus abdominis muscle. Eight months later, the scaffold and surrounding titanium cage were transferred to the patient's jaw. Vascularised living bone tissue was reported and dental implants were successfully made four months later [7]. In situations where little autologous bone is available, as in children, adipose tissue represents a good potential source of cells. Lendeckel and colleagues [59] reported the use of ADSCs to supplement autologous bone material in the successful repair of calvarial defects in a 7year-old patient: bone grafts were mixed with fibrin glue and ADSCs were injected into the grafts in a single operational procedure. Applying similar techniques, 13 patients were treated with cultured ADSCs implanted on either bioactive glass (BAG), $\beta$-TCP, or "ChronOS" (Mathys, Switzerland) synthetic $\beta$-TCP granules, with or without the addition of BMP-2. In 10 of the 13 cases successful bone integration and repair was reported [8].

The unfractioned lipoaspirate, or stromal vascular fraction (SVF), "consists of a heterogeneous population of cells that includes not only adipose, stromal, and hematopoietic stem and progenitor cells, but also endothelial cells, erythrocytes, fibroblasts, lymphocytes, monocyte/macrophages and pericytes, among others" [64]. Using the SVF, an autogenic osteogenic graft prepared using a perfusion bioreactor system could be ready for implantation in 5 days, as compared to 3 weeks when using bone marrow derived cells [65]. Additionally, the greater proliferative capacity of SVF cells $[58,62]$ and the presence of vasculature-forming endothelial cells $[65,66]$ may permit their application to intraoperative procedures [17, 67], reducing operative duration and associated morbidity. Animal studies suggest that SVF holds merit as a viable BTE cell source $[67,68]$.

\subsection{Definition of a Multipotent Mesenchymal Stromal Cell} Population. Owing to doubts about the validity of comparisons made between different studies using stromal cells from different tissues, the International Society for Cellular Therapy (ISCT) outlined a set of minimal criteria for the identification of multipotent mesenchymal stromal cells, stipulating that the cells must be plastic-adherent, express CD105 (endoglin), CD73 (ecto-5' -nucleotidase), CD90 (Thy1) and lack expression of CD45 (lymphocyte common antigen), CD34 (CD34 ${ }^{+}$cells were included in updated version of the statement to include SVF cells [64]), CD14, or CD11b (ITGAM), CD79a (MB1), or CD19 and HLA-DR surface molecules, and, finally, differentiate to osteoblasts, adipocytes, and chondroblasts in vitro [69].

A number of problems exist with these criteria: the use of plastic adherence as a requirement encourages the use of two-dimensional (2D) culture which has been associated with a loss of cell motility, proliferative activity [70], and osteogenic potential [71, 72]. The 2D environment alters cellular behaviour and may negatively affect both ADSC and BMSC development [73]. Furthermore, not all osteoprogenitors are necessarily adherent to culture dishes, BMderived mesenpheres, for example [44]. The stipulation that in vitro cultured cells can be forced to differentiate into chondrocytes, osteocytes, and marrow adipocytes, following 
prolonged, constant concentrations of differentiation factors, is at odds with the variation over time in the levels of these agents in vivo (reviewed in [74]) and results suggesting that resident stem cell populations have an intrinsic tendency to differentiate into the lineages of their resident tissue [58, 75-77], perhaps through epigenetic programming [75]. This last point is exemplified by results indicating that skeletal genes are upregulated in undifferentiated BMSCs that are unchanged in ADSCs [78] and the same BMSCs require no induction to form bone/bone marrow in vivo [78], while other sources of stromal cells require chemical [18, 19, 79] or genetic [17] induction. This may be significant when one considers the potential effects of long-term exposure of cells to inductive agents; BMP-2, for example, has been linked to the malignant transformation of breast cells [12], ectopic bone growth [10], and neurotoxicity [13]. Consideration must be given also to the methods by which differentiation into the three skeletal lineages is assessed; initial studies which reported the successful differentiation of non-BM cells into skeletal lineages did so on the basis of one histological stain per lineage. The combined use of histology, surface markers, multiple gene analysis, or proteomics would make for a more robust analysis of cellular developmental state (as used by Murata et al. [20]). Lastly, while many studies have found the ISCT marker profile between ADSCs and BMSCs to be identical $[78,80]$, others have noted significant differences in the two cell populations particularly in the expression of CD106 [16, 64] and CD36 [64]. It seems clear that ADSC and BMSC are far from identical: a salient point is their differing propensity to form cartilage, bone, and fat tissues, possibly due to epigenetic factors [75]. Therefore the interchangeable use of "MSC" to describe both (as well as stromal cells derived from other tissues) is inaccurate, and its discontinuation has been called for $[81,82]$. An indication of the cell source is crucial; thus "BMSC" and "ADSC" or term or a similar term ought to be used to clarify the tissue of origin at the very least.

2.5. BM and AT: Promising Cell Sources for BTE, but Not without Hurdles to Clinical Use. The demonstrated benefit of BMSC-based BTE $[6,51,52]$ is backed up by a number of recent studies proposing candidates for the skeletal progenitor [43-45, 83] and others showing the innate osteochondral propensity of BMSCs $[53,78,84,85]$ (Table 1 ). The ability of the SSC within the BMSC population to generate a functional bone/bone marrow organ $[4,43,84]$ places them as the prime candidate for regeneration of bone tissues. If the native physiological state of bone tissue is to be recreated then the ability to form the HME, where the SSC and HSC reside, is of paramount importance.

The clinical success of ADSC-based methods [7, 8, 20, 56] (Table 1) suggests that nonbone tissues can indeed be coaxed into forming mature bone. The lack of evidence for HMEsupport [86] casts doubt on the use of cells from this source, but given the evidence that they can be used to achieve successful bone repair coupled with the ease of collection and abundance (cf. BMSCs) $[60,72]$ the speed at which they can be prepared and replaced into the defect site [87] and their resistance to senescence $[54,88]$ and malignant transformation [89] ADSCs hold great potential for BTE.
Challenges facing the BTE field include the elucidation of the mechanisms underlying the developmental pathways involved in bone regeneration/repair and substantial task of bringing BTE technologies to the clinic at a cost that is on a par with current techniques.

\section{Developmental Engineering}

Initial hopes for the application of tissue engineering to the repair and regeneration of bone have not yet come to fruition. Unfortunately, the unmet clinical need which generated the enthusiasm surrounding TE in the 1990s [90] persists today [60]. Developments, particularly in animal models (see previous section), have advanced the field, but the resulting clinical impact has been limited.

3.1. Advancing the "Cells + Cytokines" Model of BTE. Traditionally, BTE has focused on tissue replacement through the in vitro/ex vivo generation of implants which effectively mimic the mature tissue as it is found in the adult. This has been achieved through the use of different cells, scaffold materials, and soluble factors to create a mechanical/biochemical profile that is similar to the tissue it is designed to replace [90]. Scaffolds give physical strength, durability, malleability, and three-dimensional structure, allowing for custom-sized implants with specific mechanophysical characteristics. The choice of scaffold is not insignificant as the architecture, rigidity, and biochemical properties can modulate cell differentiation. Different scaffold materials can be combined [91] or supplemented with growth factors such as BMPs [10]. Various combinations of growth factors are routinely used to guide cell differentiation towards the desired phenotype; however the use of a limited number of factors is a long way from the complexity seen in vivo $[60,92]$. Bioreactors using controlled perfusion of media through three-dimensional scaffolds recapitulate, to some degree, mechanical $[93,94]$ and hydrostatic forces [95], representing a step towards replicating the tempospatial complexity of the in vivo microenvironment, something which may well be impossible to recreate in vitro.

In recent years a number of laboratories have adopted strategies which do not conform to the standard "cells + scaffold + cytokines" approach that typifies the majority of BTE studies, instead opting for a "developmental engineering" (DE) approach [21, 22]. Just as the transition from two-dimensional to three-dimensional in vitro cell culture [72] recognised the merits of more faithfully replicating in vivo spatial relationships [70], the transition from TE to $\mathrm{DE}$ attempts to take into account the complexity of in vivo developmental processes and to incorporate features found therein for the design and generation of developmental templates.

3.2. Key Concepts of Developmental Engineering. Recently, Lenas et al. [21, 22] described a fusion of engineering principles and concepts from developmental biology, which they termed "developmental engineering." The authors outlined the utility of applying concepts such as path-dependence, 


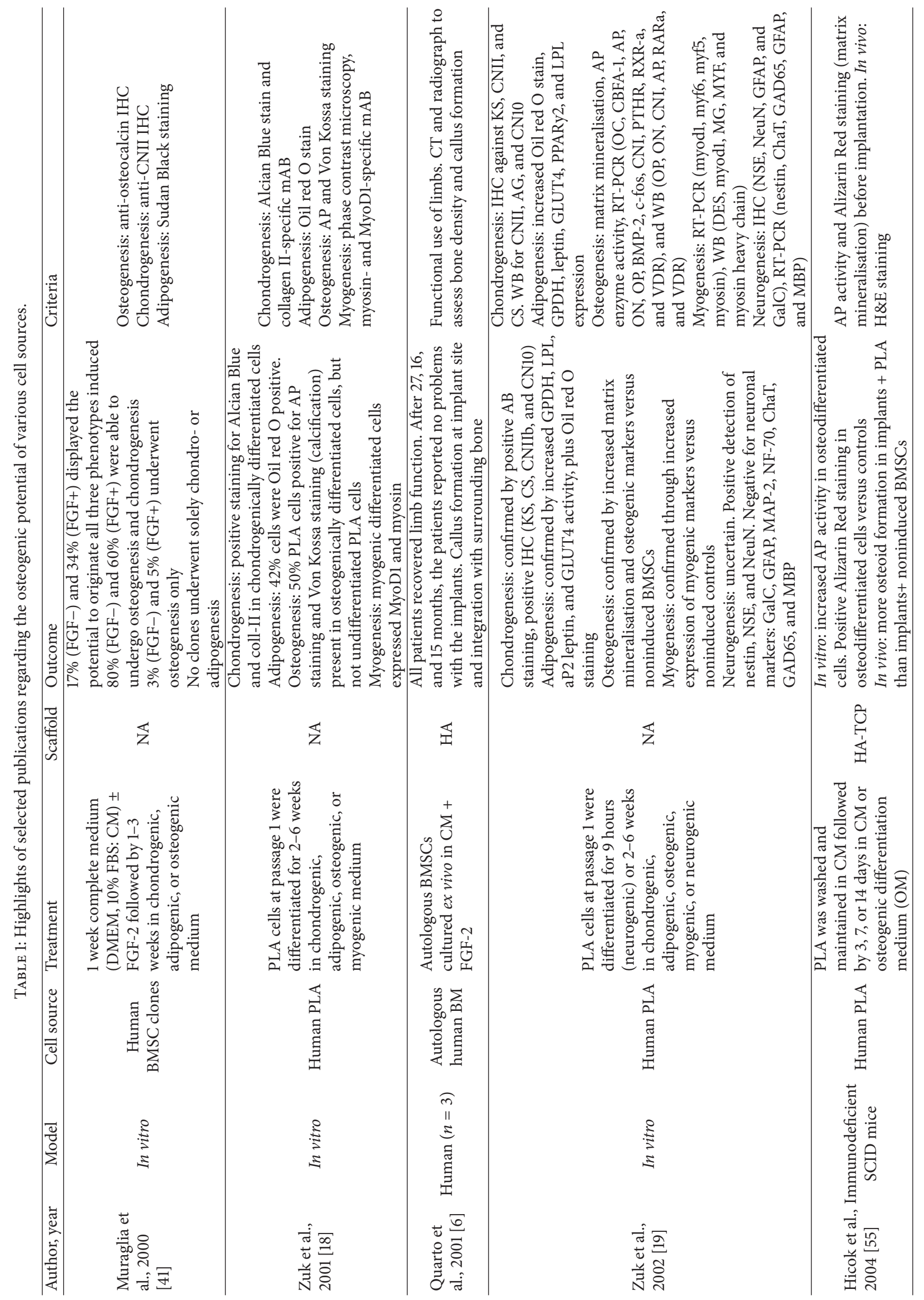




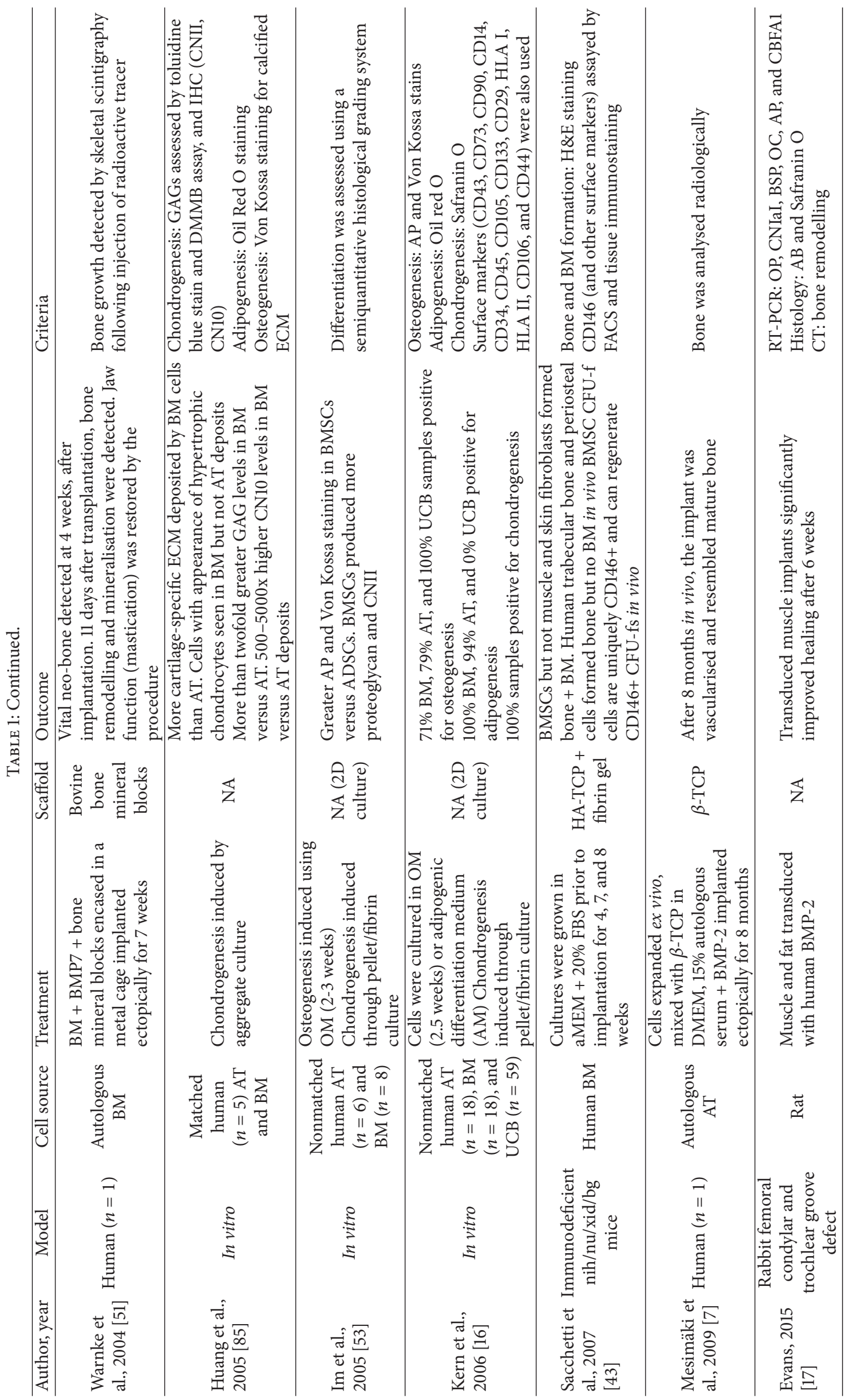




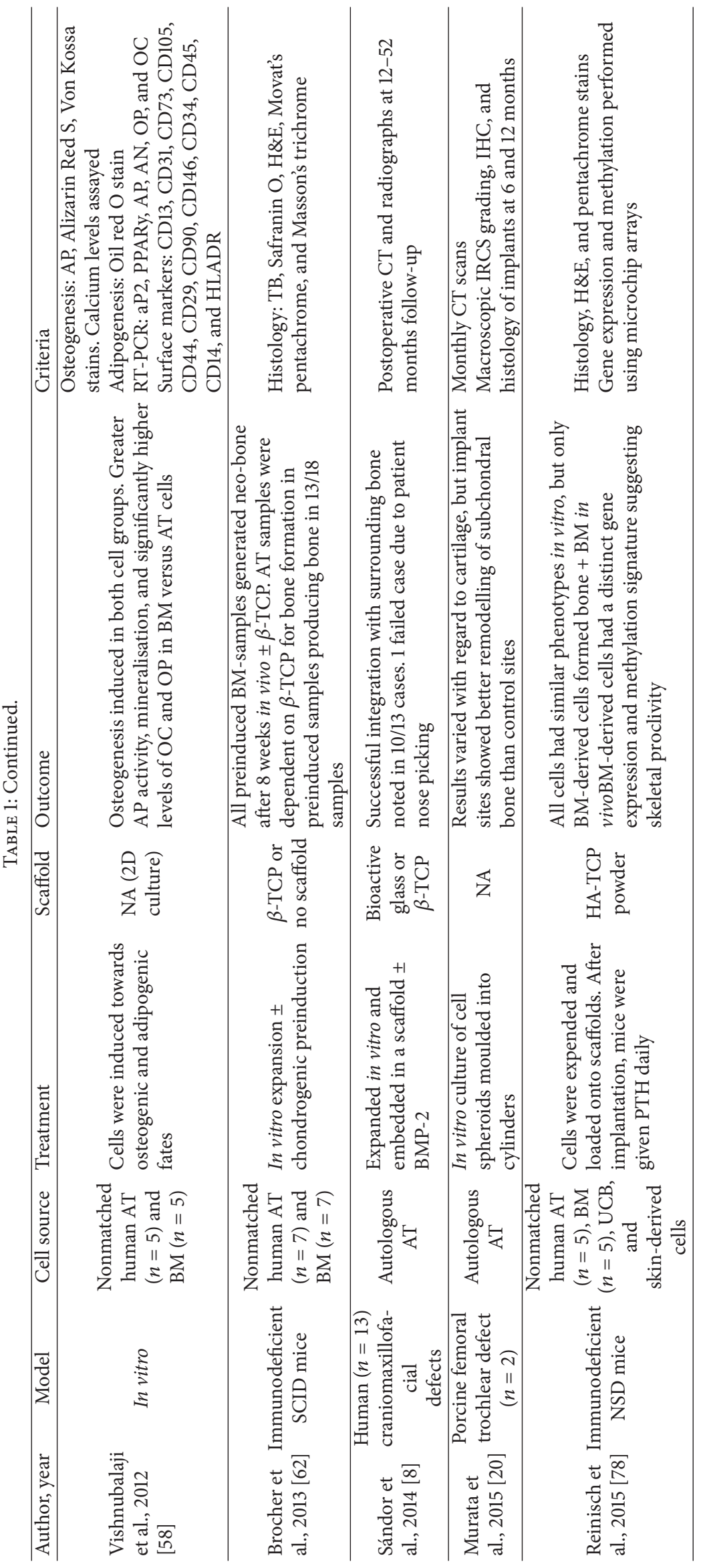


robustness, and modularity, to the manufacture of tissue grafts/implants. Robustness, within the context of developmental processes, refers to the ability of a system to function consistently despite external fluctuations. A robust developmental mechanism would therefore be able to cope with a degree of dissimilarity between the native tissue and the implant. A problem encountered when trying to gauge the characteristics necessary for successful stimulation of native repair processes is one of sensitivity; the basic tools and the limited sensitivity of currently applied methods means we are not yet able to predict whether a certain implant will function effectively, leading to much trial and error. However, the modularity of many developmental processes permits ex vivo experimentation to determine optimal conditions and timing for implantation to achieve the best results in vivo [84, 96]. Additionally, ex vivo experiments can be used to identify markers for the successful completion of multistage developmental processes [22, 97]. In this fashion, the progress of the implant can be monitored, in vivo, through the stages of development, highlighting where problems lie and thus where refinement is needed. The successful completion of each step of development sets the stage for the next step, providing optimal conditions. This concept, rooted in economics, law [98], and biology, is called path-dependence and describes a situation where the outcome of one process directly influences the effectiveness of a successive process. Thus, one process acts as a check-point for the correct completion of the previous step, and at the same time completion of the previous step sets the stage for the following stages. In the context of bone regeneration, this is exemplified by hypertrophic chondrocytes which act as a natural scaffold for osteogenesis as well as secreting factors which orchestrate the differentiation of osteoblasts from perichondrial cells, as well as the mineralisation and vascularisation of the neo-bone tissue, restoring normoxic conditions required for optimal bone growth and bringing vital materials [99]. This concept has experimental support; hypertrophic chondrocytes have been shown to stimulate bone regeneration in vivo, while lesser developed tissues were not as effective in stimulating the formation of bone tissue, likely reflecting the pathdependence of this process $[28,84]$. Indeed, BMSCs have been demonstrated to follow the endochondral route when chondrogenically primed and implanted in a vascularised tissue [25]. The use of a hypertrophic differentiation medium accelerates and makes the process more efficient.

Instead of aiming to phenocopy the adult tissue-state, researchers are drawing on the work of developmental biology, which states that "normal tissue healing in the adult involves progressive remodelling of pre-existing tissue structures" [90] to generate grafts that recapitulate the immature tissue-state. By implanting the precursor state of a tissue, or "organ germ" [57, 100], elements of the implant can interact with natural developmental cues to regulate differentiation and growth and to provide cues for cell invasion, remodelling, and revascularisation in the correct spatiotemporal context. In this manner we might overcome one of the greatest challenges facing TE, that is, effectively mimicking the complexity of natural developmental processes, thereby leading to formation of an authentic mature tissue.
Considering that the vast majority of bones develop through endochondral ossification, an endochondral approach to bone regeneration is now considered "developmental engineering." However, the endochondral approach per se does not make "developmental engineering" a bone regeneration strategy. In fact, flat bones of the head develop through intramembranous ossification.

\subsection{Recapitulation of Endochondral Ossification through} Chondrogenic Differentiation. Historically, TE has directed the formation of neo-bone through the intramembranous route relying on the presence of mineralised substrate scaffolds to initiate bone growth through intramembranous ossification; however more recently numerous studies have illustrated the advantages of bone formation through endochondral ossification $[25,29,41,84,91,96,101,102]$. Endochondral ossification is the method by which the axial and long bones of the skeleton (the vast majority of bones) are formed during embryogenesis [103] and has many features common to bone regeneration after fracture $[104,105]$ including activation of key signalling pathways such as Indian hedgehog (IHH), parathyroid-related hormone protein (PTHrP), wingless (wnt), and BMPs (although, notably, the postnatal environment differs from that of the developing embryo [104]). The process entails the condensation (clustering together through cell surface receptors and adhesion molecules [106]) of chondrocytes, which secrete a collagenous (type II) matrix rich in proteoglycans. Under the control of two of the master regulators of bone development, $\mathrm{IHH}$, and PTHrP (see [103]), chondrocytes at the centre of the proto-bone organ cease to proliferate and become enlarged (hypertrophic), producing large amounts of type X collagen, directing initial mineralisation [107] and vascularisation through VEGF production, before undergoing apoptosis, to leave a cartilage scaffold that will eventually be remodelled into mature bone [103]. This strategy has been exploited for bone regeneration; implantation of hypertrophic huBMSCs in nude mice has been demonstrated to lead to the growth of ectopic bone structures as a result of human cells playing an active role of osteogenesis [25]. BMSCs embedded in $\beta$ TCP scaffolds were able to generate frank bone in vivo, but chondrogenic priming was necessary for the production of bone + BM [96], while huBMSCs seeded on collagen type I scaffolds induced towards endochondral ossification formed not only bone organs, but also a fully functional BM which was shown to sustain haematopoiesis in lethally irradiated mice [84]. In a previous study cells that were not hypertrophic at the time of implantation failed to generate bone and were resorbed, indicating that the developmental stage is a critical factor in dictating whether the implant will proceed to the next stage $[25,108]$.

There are multiple advantages to implanting chondrogenically primed cells: chondrocytes are more likely to survive the hypoxic in vivo environment [101]; they stimulate vascularisation $[101,109]$ through secretion of VEGF [109] and have been shown to increase bone formation in vivo through BMP production [60]. Additionally, by selecting a stating material which most closely matches the in vivo precursor to 
the tissue of interest and by guiding those cells through developmental stages using known markers, an intermediate form of the tissue is generated which "contains all the necessary and sufficient instructive elements for its regeneration" [110]. This has obvious implications for the choice of cell source, since a cell containing detectable genetic, epigenetic, proteomic modifications which are optimal for a particular developmental path is not only more likely to produce a higher quality final product, but also likely to contain additional characteristics which the limited and basic range of tests at our disposal cannot gauge. That said, ADSCs, which had low intrinsic bone-forming potential and produced no neo-bone in their uninduced state, when chondrogenically primed deposited a proteoglycan-rich cartilaginous matrix and were able to generate a similar amount of bone as uninduced BMSCs [62]. This suggests that, by rerouting ADSCs through endochondral ossification, a precursor state is created that favours bone formation. It is noteworthy that despite the successful rerouting of ADSCs, uninduced BMSCs achieved better final results, perhaps reflecting intrinsic factors that predispose them to bone formation $[62,75]$.

3.4. Considerations and Limitations of Mimicking Embryogenesis for BTE. While the adoption of processes which mimic embryogenesis has demonstrated merit $[84,96]$, there are salient physical, biochemical, mechanical, and immunological differences between the developing embryo and a mature tissue microenvironment $[60,92,104,111]$. Accordingly, we must adjust the design of prospective implants to reflect these differences [26]. Embryonic development occurs under different immunological and inflammatory settings as well as at a much smaller scale than in the adult; both of these factors must be addressed if embryonic processes are to be harnessed for the successful engineering of bone grafts.

Paracrine signalling gradients which function at the embryonic scale are likely to be inefficient in a much larger graft. Modular implants, comprising many smaller units, may be utilised to overcome this hurdle (modular implantscellular sheets [112]) in addition to addressing some of the limitations of mass transfer such as necrosis at the core of the engineered tissue.

The immunological milieu controlling developmental processes and the influx of cells at the embryonic stage of bone growth remains to be fully elucidated. This is likely to be a crucial step if we are to fully harness the potential of developmental engineering, as immune factors are significant mediators of bone healing and regrowth [104], which can result in retardation of healing if suppressed $[111,113]$. Interestingly, this last point serves to highlight the differences between developmental processes underway during embryogenesis and those involved in the adult: while inflammation represents one of the main drivers of bone repair $[84,111]$, it is absent during normal bone development. In fact, the significance of interleukin- $1 \beta$ (IL- $1 \beta$ ) in the revascularisation, mineralisation, and cartilage remodelling activity of huBMSCs has been illustrated [111, 114].

In conclusion, the adoption of a developmental engineering paradigm for the regeneration of bone represents a potential method to mitigate the enormous hurdle presented by largely unknown in vivo complexity. By generating precursor organ germs based on observable in vitro elucidated markers and allowing natural cues to orchestrate the development of hypertrophic chondrocyte templates, it is foreseeable that future bone repair strategies will achieve clinical use. However, if we are to effectively utilise this technique, a clearer more complete understanding of the biochemical and mechanical forces at work in both the developing embryo and the adult is required.

\section{Implications of Scaffold Technology for Cell versus Cell-Free Approaches}

With the objective of repairing bone in a manner which recalls natural healing processes, both cell-based and cellfree methods have been utilised: both have advantages, but currently cell-based therapeutic strategies are the status quo. This usually comprises BMSCs which have been extracted and either reinjected intraoperatively or cultured ex vivo for several passages to generate many more cells which are then reinjected in their current state, or, more commonly, seeded on a three-dimensional scaffold material. Innovations in the preparation of scaffold materials have added an additional dimension to current BTE treatments and may pave the way to standardized, off-the-shelf in vitro derived cell-free products in clinical bone repair.

4.1. Cells or No Cells? Cell-based strategies, most often utilising BMSCs, have been shown to be more successful at stimulating bone healing than cell-free approaches, resulting in greater mineralisation, ossification, and increased angiogenic potential $[27-29,48,49]$. These results are supported by data showing cell-based techniques to be clinically advantageous $[115,116]$. However, the downsides to autologous cell-based therapy are significant and can be prohibitive in some cases. The rarity of BMSCs can be limiting to the point of rendering cell extraction unfeasible (especially in the elderly and the ill) and too few CFU-f within a BM extract will fail to generate neo-bone tissue $[72,117]$. Even in healthy individuals, cell extraction requires an additional procedure which carries added morbidity. Eliminating the need for extra surgery has strongly motivated the development of intraoperative techniques which, while avoiding the time-expensive and laborious GMP handling of cells in the laboratory, are also limited by the number of BMSCs available for reinjection.

Cell-free technologies have been proposed as an alternative to sidestep many of the barriers associated with cell-based techniques for bone-specific and other areas of tissue engineering. A product which is available "off-the-shelf" following decellularisation and sterilisation has obvious practical advantages from a surgical perspective such as the reduction of intrapatient variability and would allow the selection and preparation of the implant prior to surgery. Additionally, the implant can be recellularised with autologous BMSCs prior to use if sufficient cells are available [29]. Also, a sterile acellular product would be amenable to storage and thus easily transported to areas of need where the resources for 
preserving cell-based products might be lacking. All of these reasons would act to increase the clinical uptake.

\subsection{Decellularised ECM as a Biological Scaffold for BTE.} Many recent studies have attempted to mimic the inherent complexity of the biological microenvironment, in terms of architecture and biochemical constituents, through the use of decellularised extracellular matrix (ECM) from a variety of animal sources, both human $[118,119]$ and nonhuman $[120$, 121]. The latter option presents the possibility of benefiting from existing slaughter processes to access a large volume of material for decellularisation. The risk of zoonoses, especially prion diseases, can be reduced by sourcing animals from prion-free island populations $[122,123]$. The use of cell lines derived from either human or nonhuman animals to produce a functional ECM that could subsequently be decellularised presents the possibility of standardisation, reducing donorto-donor variability [9].

For the successful application of allogenic or xenogenic sources, the implants must be effectively decellularised to avoid a damaging immune response. The decellularisation protocol represents a balancing act between preserving the native biochemistry and microstructure and simultaneously removing cells and other immunogenic materials. Decellularisation is achieved primarily through physical/mechanical (predominantly freeze-thaw), chemical (including detergentbased methods), and enzymatic means coupled to wash steps to remove debris (extensively reviewed in [124]). Any treatment is almost certain to disrupt the native structure, either physically or biochemically, and therefore strip away many of the growth factors, cytokines, and inflammatory factors harboured within the ECM.

With regard to bone engineering, the modern concept of developmental engineering suggests that the endochondral route provides the optimal template. Previously, hypertrophic chondrocytes derived from human BMSCs were shown to be remodelled and replaced by frank bone tissue, including a functional haematopoietic compartment [24]. Accordingly, decellularised hypertrophic cartilage has been used as a template to stimulate the regeneration of bone material through endochondral pathways, promoting the invasion and proliferation of host cells [27-29]. Induced apoptosis of hypertrophic chondrocytes has recently been proposed to decellularise ECM for bone regeneration through the retroviral transduction of a chemically inducible caspase9-bearing construct. This was shown to be superior to a standard freeze-thaw protocol for the regeneration of bone. Postapoptotic cartilage and implants containing live BMSCs, but not nonhypertrophic cartilage, underwent extensive remodelling and after 12 weeks in vivo tested positive for the presence of a BM space, although implants containing live cells outperformed the "apoptosed" tissue [27]. Elsewhere, nonhypertrophic cartilage was shown to be inferior to hypertrophic constructs in a mouse femoral defect model, where only the latter were successful in bridging the defect [28].

To date, the use of cell-free techniques has yet to demonstrate equivalence to cell containing preparations. Developments in the methods used for decellularisation will undoubtedly result in more effective scaffold materials, due to greater retention of ECM-associated molecules with simultaneous removal of cellular material, to yield bone engineering products with off-the-shelf convenience, as well as low-maintenance storage, and increased customisation. Advances in scaffold preparation techniques, with or without autologous cells, likely represent an area of keen future research interest.

\section{Conclusions}

Intrinsic bone repair mechanisms are highly effective, but in certain cases external intervention is required. In some instances, BTE has been shown to provide clinical relief, but improvement in BTE technologies is required to allow its application to greater numbers of patients, particularly those to whom traditional bone grafting procedures are unfeasible.

Recent strategies in bone repair and regeneration have sought to embrace a developmental engineering approach, following as closely as possible the natural processes of bone development through the remodelling of hypertrophic cartilage templates via endochondral ossification. The predominant use of BMSCs for bone formation following the endochondral route reflects the role of the $\mathrm{BM}$ as the natural reservoir of skeletal-tissue forming cells, namely, the SSC, and illustrates their propensity to differentiate into skeletal lineages.

BMSCs form bone $+\mathrm{BM}$ in vivo which is essential if creation of the HME is required. The factors (genetic, epigenetic, proteomic, etc.) responsible for the predestination of BMSC to form functional bone $+\mathrm{BM}$ are unknown, and we cannot currently quantify the extent of these "unknown unknowns" [125]. Likely a fraction of these factors driving BMSC to form bone $+\mathrm{BM}$ will also regulate additional steps in skeletal development and remodelling allowing cells to correctly react to autocrine and paracrine developmental signals. Until we have a clearer understanding of the mechanisms underlying bone development, BMSCs represent a more rational choice for bone regeneration and repair if long-term propagation of bone tissues (and haematopoietic cells) is desired.

This last point assumes the availability of autologous BMSCs, which is not always the case. ADSCs are championed by their proponents for their far greater accessibility and the presence of greater numbers of CFU-f per unit volume than that found in the BM. Clinical evidence of the efficacy of ADSC-based therapy indicates that AT is an excellent source for cells for the generation of bone tissue. Is this a question of quantity over quality though? Where simple bone tissue is called for rather than a functional bone-BM organ, it may be the case that ADSC-derived bone is "good enough." This, coupled with the great advantages of using ADSCs, may be enough to ensure the continued application and development of ADSCs to bone repair.

Regardless of cell source, currently live cell-based implants tend to be superior to cell-free and decellularised alternatives at regenerating bone tissue. Recent advances in decellularisation protocols are bringing the performance of decellularised and devitalised tissues to ever greater levels, 
approaching that of vital implants, with the added value of storage, transportation, and the possibility of allogenic or xenogenic-derived grafts to circumgate the difficulties in obtaining autologous cells for bone regeneration and repair. Another valuable strategy to improve the results of decellularised matrices is based on the intraoperative recellularisation of the graft. In fact, it is nowadays possible to recellularise a decellularised matrix with autologous bone marrow cells, or fat-derived stromal and vascular cells. Future research should be focused on developing effective and sustainable clinically compliant bone regeneration strategies that combine the efficacy of cell-based therapies with the superior practical features of decellularised matrices.

\section{Abbreviations}

$\beta$-TCP: Beta tricalcium phosphate

HA: Hydroxyapatite

PLA: $\quad$ Processed lipoaspirate

PTHrP: Parathyroid hormone related protein

SVF: $\quad$ Stromal vascular fraction

AB: $\quad$ Alcian Blue

ADSC: Adipose-derived stromal cell

AG: Aggrecan

AN: Adiponectin

AP: Alkaline phosphatase

AT: $\quad$ Adipose tissue

BM: Bone marrow

BMSC: Bone marrow stromal cell

BSP: Bone sialoprotein

BTE: Bone tissue engineering

CBFA-1: Core-binding factor alpha 1

ChaT: Choline acetyltransferase

CNI: Collagen type I

CNII: Collagen type II

CN10: Collagen type 10

CS: Chondroitin-4-sulfate

DE: Developmental engineering

DES: Desmin

ECM: Extracellular matrix

GLUT4: Glucose transporter type 4

GPDH: Glycerol-3-phosphate dehydrogenase

HME: Haematopoietic microenvironment

HSC: Haematopoietic stem cell

ICRS: International Cartilage Repair Society

IHC: Immunohistochemistry

KS: $\quad$ Keratan sulfate

LPL: Lipoprotein lipase

mAB: Monoclonal antibody

MBP: Myolin basic protein

MG: Myogenin

MYF: Myogenic regulatory factor

NeuN: Neuronal nuclei protein

NSE: Neuron-specific enolase

OC: Osteocalcin

ON: Osteonectin

OP: Osteopontin

PPARy: Peroxisome-proliferating associated receptor-y

PTH: Parathyroid hormone
PTHR: Parathyroid hormone receptor

RARa: Retinoic acid receptor alpha

RT-PCR: Real time PCR

RXRa: Retinoid X receptor alpha

SSC: $\quad$ Skeletal stem cell

TE: $\quad$ Tissue engineering

UCB: Umbilical cord blood

VD: $\quad$ 1,25-Dihydroxyvitamin D3

VDR: Vitamin D receptor

WB: western blotting.

\section{Conflict of Interests}

The authors declare that there is no conflict of interests regarding the publication of this paper.

\section{References}

[1] J. S. Silber, D. G. Anderson, S. D. Daffner et al., "Donor site morbidity after anterior iliac crest bone harvest for single-level anterior cervical discectomy and fusion," Spine, vol. 28, no. 2, pp. 134-139, 2003.

[2] A. J. Friedenstein, I. I. Piatetzky-Shapiro, and K. V. Petrakova, "Osteogenesis in transplants of bone marrow cells," Journal of Embryology and Experimental Morphology, vol. 16, no. 3, pp. 381-390, 1966.

[3] M. Tavassoli and W. H. Crosby, "Transplantation of marrow to extramedullary sites," Science, vol. 161, no. 3836, pp. 54-56, 1968.

[4] P. Bianco, X. Cao, P. S. Frenette et al., "The meaning, the sense and the significance: translating the science of mesenchymal stem cells into medicine," Nature Medicine, vol. 19, no. 1, pp. 3542, 2013.

[5] A. Keating, "Mesenchymal stromal cells: new directions," Cell Stem Cell, vol. 10, no. 6, pp. 709-716, 2012.

[6] R. Quarto, M. Mastrogiacomo, R. Cancedda et al., "Repair of large bone defects with the use of autologous bone marrow stromal cells," The New England Journal of Medicine, vol. 344, no. 5, pp. 385-386, 2001.

[7] K. Mesimäki, B. Lindroos, J. Törnwall et al., "Novel maxillary reconstruction with ectopic bone formation by GMP adipose stem cells," International Journal of Oral and Maxillofacial Surgery, vol. 38, no. 3, pp. 201-209, 2009.

[8] G. K. Sándor, J. Numminen, J. Wolff et al., "Adipose stem cells used to reconstruct 13 cases with cranio-maxillofacial hardtissue defects," Stem Cells Translational Medicine, vol. 3, no. 4, pp. 530-540, 2014.

[9] Z. Schwartz, A. Somers, J. T. Mellonig et al., "Ability of commercial demineralized freeze-dried bone allograft to induce new bone formation is dependent on donor age but not gender," Journal of Periodontology, vol. 69, no. 4, pp. 470-478, 1998.

[10] H. Deutsch, "High-dose bone morphogenetic protein-induced ectopic abdomen bone growth," The Spine Journal, vol. 10, no. 2, pp. el-e4, 2010.

[11] M. Vilalta, I. R. Dégano, J. Bagó et al., "Biodistribution, longterm survival, and safety of human adipose tissue-derived mesenchymal stem cells transplanted in nude mice by high sensitivity non-invasive bioluminescence imaging," Stem Cells and Development, vol. 17, no. 5, pp. 993-1003, 2008.

[12] M. Chapellier, E. Bachelard-Cascales, X. Schmidt et al., "Disequilibrium of BMP2 levels in the breast stem cell niche 
launches epithelial transformation by overamplifying BMPR1B cell response," Stem Cell Reports, vol. 4, no. 2, pp. 239-254, 2015.

[13] D. M. Smith, G. M. Cooper, M. P. Mooney, K. G. Marra, and J. E. Losee, "Bone morphogenetic protein 2 therapy for craniofacial surgery," Journal of Craniofacial Surgery, vol. 19, no. 5, pp. 12441259, 2008.

[14] M. S. Rahman, N. Akhtar, H. M. Jamil, R. S. Banik, and S. M. Asaduzzaman, "TGF- $\beta /$ BMP signaling and other molecular events: regulation of osteoblastogenesis and bone formation," Bone Research, vol. 3, article 15005, 2015.

[15] P. M. Siegel and J. Massagué, "Cytostatic and apoptotic actions of TGF- $\beta$ in homeostasis and cancer," Nature Reviews Cancer, vol. 3, no. 11, pp. 807-820, 2003.

[16] S. Kern, H. Eichler, J. Stoeve, H. Klüter, and K. Bieback, "Comparative analysis of mesenchymal stem cells from bone marrow, umbilical cord blood, or adipose tissue," STEM CELLS, vol. 24, no. 5, pp. 1294-1301, 2006.

[17] C. H. Evans, "Native, living tissues as cell seeded scaffolds," Annals of Biomedical Engineering, vol. 43, no. 3, pp. 787-795, 2015.

[18] P. A. Zuk, M. Zhu, H. Mizuno et al., "Multilineage cells from human adipose tissue: implications for cell-based therapies," Tissue Engineering, vol. 7, no. 2, pp. 211-228, 2001.

[19] P. A. Zuk, M. Zhu, P. Ashjian et al., "Human adipose tissue is a source of multipotent stem cells," Molecular Biology of the Cell, vol. 13, no. 12, pp. 4279-4295, 2002.

[20] D. Murata, S. Tokunaga, T. Tamura et al., "A preliminary study of osteochondral regeneration using a scaffold-free threedimensional construct of porcine adipose tissue-derived mesenchymal stem cells," Journal of Orthopaedic Surgery and Research, vol. 10, article 35, 2015.

[21] P. Lenas, M. Moos, and F. P. Luyten, "Developmental engineering: a new paradigm for the design and manufacturing of cell-based products. Part II. From genes to networks: tissue engineering from the viewpoint of systems biology and network science," Tissue Engineering Part B: Reviews, vol. 15, no. 4, pp. 395-422, 2009.

[22] P. Lenas, M. Moos, and F. P. Luyten, "Developmental engineering: a new paradigm for the design and manufacturing of cellbased products. Part I: From three-dimensional cell growth to biomimetics of in vivo development," Tissue Engineering-Part B: Reviews, vol. 15, no. 4, pp. 381-394, 2009.

[23] M. M. Stevens, R. P. Marini, D. Schaefer, J. Aronson, R. Langer, and V. P. Shastri, "In vivo engineering of organs: the bone bioreactor," Proceedings of the National Academy of Sciences of the United States of America, vol. 102, no. 32, pp. 11450-11455, 2005.

[24] C. Scotti, M. T. Hirschmann, P. Antinolfi, I. Martin, and G. M. Peretti, "Meniscus repair and regeneration: review on current methods and research potential," European Cells and Materials, vol. 26, pp. 150-170, 2013.

[25] C. Scotti, B. Tonnarelli, A. Papadimitropoulos et al., "Recapitulation of endochondral bone formation using human adult mesenchymal stem cells as a paradigm for developmental engineering," Proceedings of the National Academy of Sciences of the United States of America, vol. 107, no. 16, pp. 7251-7256, 2010.

[26] B. Tonnarelli, M. Centola, A. Barbero, R. Zeller, and I. Martin, "Re-engineering development to instruct tissue regeneration," Current Topics in Developmental Biology, vol. 108, pp. 319-338, 2014.
[27] P. E. Bourgine, C. Scotti, S. Pigeot, L. A. Tchang, A. Todorov, and I. Martin, "Osteoinductivity of engineered cartilaginous templates devitalized by inducible apoptosis," Proceedings of the National Academy of Sciences of the United States of America, vol. 111, no. 49, pp. 17426-17431, 2014.

[28] G. M. Cunniffe, T. Vinardell, J. M. Murphy et al., "Porous decellularized tissue engineered hypertrophic cartilage as a scaffold for large bone defect healing," Acta Biomaterialia, vol. 23, pp. 82-90, 2015.

[29] D. Gawlitta, K. E. Benders, J. Visser et al., "Decellularized cartilage-derived matrix as substrate for endochondral bone regeneration," Tissue Engineering Part A, vol. 21, no. 3-4, pp. 694-703, 2015.

[30] A. Erices, P. Conget, and J. J. Minguell, "Mesenchymal progenitor cells in human umbilical cord blood," British Journal of Haematology, vol. 109, no. 1, pp. 235-242, 2000.

[31] K. E. Mitchell, M. L. Weiss, B. M. Mitchell et al., "Matrix cells from Wharton's jelly form neurons and glia," STEM CELLS, vol. 21, no. 1, pp. 50-60, 2003.

[32] S. Gronthos, M. Mankani, J. Brahim, P. G. Robey, and S. Shi, "Postnatal human dental pulp stem cells (DPSCs) in vitro and in vivo," Proceedings of the National Academy of Sciences of the United States of America, vol. 97, no. 25, pp. 13625-13630, 2000.

[33] C. L. Radtke, R. Nino-Fong, B. P. Esparza Gonzalez, H. Stryhn, and L. A. McDuffee, "Characterization and osteogenic potential of equine muscle tissue- and periosteal tissue-derived mesenchymal stem cells in comparison with bone marrowand adipose tissue-derived mesenchymal stem cells," American Journal of Veterinary Research, vol. 74, no. 5, pp. 790-800, 2013.

[34] A. J. Friedenstein, K. V. Petrakova, A. I. Kurolesova, and G. P. Frolova, "Heterotopic of bone marrow. Analysis of precursor cells for osteogenic and hematopoietic tissues," Transplantation, vol. 6, no. 2, pp. 230-247, 1968.

[35] A. J. Friedenstein, R. K. Chailakhjan, and K. S. Lalykina, "The development of fibroblast colonies in monolayer cultures of guinea-pig bone marrow and spleen cells," Cell Proliferation, vol. 3, no. 4, pp. 393-403, 1970.

[36] H. Castro-Malaspina, R. E. Gay, G. Resnick et al., "Characterization of human bone marrow fibroblast colony-forming cells (CFU-F) and their progeny," Blood, vol. 56, no. 2, pp. 289-301, 1980.

[37] A. I. Caplan, "Mesenchymal stem cells," Journal of Orthopaedic Research, vol. 9, no. 5, pp. 641-650, 1991.

[38] J. Goshima, V. M. Goldberg, and A. I. Caplan, “The osteogenic potential of culture-expanded rat marrow mesenchymal cells assayed in vivo in calcium phosphate ceramic blocks," Clinical Orthopaedics and Related Research, no. 262, pp. 298-311, 1991.

[39] S. E. Haynesworth, J. Goshima, V. M. Goldberg, and A. I. Caplan, "Characterization of cells with osteogenic potential from human marrow," Bone, vol. 13, no. 1, pp. 81-88, 1992.

[40] M. F. Pittenger, A. M. Mackay, S. C. Beck et al., "Multilineage potential of adult human mesenchymal stem cells," Science, vol. 284, no. 5411, pp. 143-147, 1999.

[41] A. Muraglia, R. Cancedda, and R. Quarto, "Clonal mesenchymal progenitors from human bone marrow differentiate in vitro according to a hierarchical model," Journal of Cell Science, vol. 113, part 7, pp. 1161-1166, 2000.

[42] C. C. Lee, J. E. Christensen, M. C. Yoder, and A. F. Tarantal, "Clonal analysis and hierarchy of human bone marrow mesenchymal stem and progenitor cells," Experimental Hematology, vol. 38, no. 1, pp. 46-54, 2010. 
[43] B. Sacchetti, A. Funari, S. Michienzi et al., "Self-renewing osteoprogenitors in bone marrow sinusoids can organize a hematopoietic microenvironment," Cell, vol. 131, no. 2, pp. 324336, 2007.

[44] S. Méndez-Ferrer, T. V. Michurina, F. Ferraro et al., "Mesenchymal and haematopoietic stem cells form a unique bone marrow niche," Nature, vol. 466, no. 7308, pp. 829-834, 2010.

[45] D. L. Worthley, M. Churchill, J. T. Compton et al., "Gremlin 1 identifies a skeletal stem cell with bone, cartilage, and reticular stromal potential," Cell, vol. 160, no. 1-2, pp. 269-284, 2015.

[46] M. Kassem and P. Bianco, "Skeletal stem cells in space and time," Cell, vol. 160, no. 1-2, pp. 17-19, 2015.

[47] S. Kadiyala, N. Jaiswal, and S. P. Bruder, "Culture-expanded, bone marrow-derived mesenchymal stem cells can regenerate a critical-sized segmental bone defect," Tissue Engineering, vol. 3, no. 2, pp. 173-185, 1997.

[48] E. Kon, A. Muraglia, A. Corsi et al., "Autologous bone marrow stromal cells loaded onto porous hydroxyapatite ceramic accelerate bone repair in critical-size defects of sheep long bones," Journal of Biomedical Materials Research, vol. 49, no. 3, pp. 328337,2000 .

[49] S. P. Bruder, K. H. Kraus, V. M. Goldberg, and S. Kadiyala, "The effect of implants loaded with autologous mesenchymal stem cells on the healing of canine segmental bone defects," The Journal of Bone \& Joint Surgery-American Volume, vol. 80, no. 7, pp. 985-996, 1998.

[50] I. Martin, A. Muraglia, G. Campanile, R. Cancedda, and R. Quarto, "Fibroblast growth factor-2 supports ex vivo expansion and maintenance of osteogenic precursors from human bone marrow," Endocrinology, vol. 138, no. 10, pp. 4456-4462, 1997.

[51] P. H. Warnke, I. N. Springer, P. J. Wiltfang et al., "Growth and transplantation of a custom vascularised bone graft in a man," The Lancet, vol. 364, no. 9436, pp. 766-770, 2004.

[52] M. Marcacci, E. Kon, V. Moukhachev et al., "Stem cells associated with macroporous bioceramics for long bone repair: 6- to 7-year outcome of a pilot clinical study," Tissue Engineering, vol. 13, no. 5, pp. 947-955, 2007.

[53] G.-I. Im, Y.-W. Shin, and K.-B. Lee, "Do adipose tissue-derived mesenchymal stem cells have the same osteogenic and chondrogenic potential as bone marrow-derived cells?" Osteoarthritis and Cartilage, vol. 13, no. 10, pp. 845-853, 2005.

[54] R. I. Dmitrieva, R. Minullina, A. A. Bilibina, O. V. Tarasova, S. V. Anisimov, and A. Y. Zaritskey, "Bone marrow-and subcutaneous adipose tissue-derived mesenchymal stem cells: differences and similarities," Cell Cycle, vol. 11, no. 2, pp. 377383, 2012.

[55] K. C. Hicok, T. V. Du Laney, Y. S. Zhou et al., "Human adipose-derived adult stem cells produce osteoid in vivo," Tissue Engineering, vol. 10, no. 3-4, pp. 371-380, 2004.

[56] J. Justesen, S. B. Pedersen, K. Stenderup, and M. Kassem, "Subcutaneous adipocytes can differentiate into bone-forming cells in vitro and in vivo," Tissue Engineering, vol. 10, no. 3-4, pp. 381-391, 2004.

[57] N. Nakao, T. Nakayama, T. Yahata et al., "Adipose tissue-derived mesenchymal stem cells facilitate hematopoiesis in vitro and in vivo: advantages over bone marrow-derived mesenchymal stem cells," The American Journal of Pathology, vol. 177, no. 2, pp. 547$554,2010$.
[58] R. Vishnubalaji, M. Al-Nbaheen, B. Kadalmani, A. Aldahmash, and T. Ramesh, "Comparative investigation of the differentiation capability of bone-marrow- and adipose-derived mesenchymal stem cells by qualitative and quantitative analysis," Cell and Tissue Research, vol. 347, no. 2, pp. 419-427, 2012.

[59] S. Lendeckel, A. Jödicke, P. Christophis et al., "Autologous stem cells (adipose) and fibrin glue used to treat widespread traumatic calvarial defects: case report," Journal of CranioMaxillofacial Surgery, vol. 32, no. 6, pp. 370-373, 2004.

[60] M. Jakob, F. Saxer, C. Scotti et al., "Perspective on the evolution of cell-based bone tissue engineering strategies," European Surgical Research, vol. 49, no. 1, pp. 1-7, 2012.

[61] L. De Girolamo, M. F. Sartori, W. Albisetti, and A. T. Brini, "Osteogenic differentiation of human adipose-derived stem cells: comparison of two different inductive media," Journal of Tissue Engineering and Regenerative Medicine, vol. 1, no. 2, pp. 154-157, 2007.

[62] J. Brocher, P. Janicki, P. Voltz et al., "Inferior ectopic bone formation of mesenchymal stromal cells from adipose tissue compared to bone marrow: rescue by chondrogenic preinduction," Stem Cell Research, vol. 11, no. 3, pp. 1393-1406, 2013.

[63] B. O. Zhou, R. Yue, M. M. Murphy, J. G. Peyer, and S. J. Morrison, "Leptin-receptor-expressing mesenchymal stromal cells represent the main source of bone formed by adult bone marrow," Cell Stem Cell, vol. 15, no. 2, pp. 154-168, 2014.

[64] P. Bourin, B. A. Bunnell, L. Casteilla et al., "Stromal cells from the adipose tissue-derived stromal vascular fraction and culture expanded adipose tissue-derived stromal/stem cells: a joint statement of the International Federation for Adipose Therapeutics and Science (IFATS) and the International Society for Cellular Therapy (ISCT)," Cytotherapy, vol. 15, no. 6, pp. 641648, 2013.

[65] A. Scherberich, R. Galli, C. Jaquiery, J. Farhadi, and I. Martin, "Three-dimensional perfusion culture of human adipose tissuederived endothelial and osteoblastic progenitors generates osteogenic constructs with intrinsic vascularization capacity," STEM CELLS, vol. 25, no. 7, pp. 1823-1829, 2007.

[66] S. Güven, A. Mehrkens, F. Saxer et al., "Engineering of large osteogenic grafts with rapid engraftment capacity using mesenchymal and endothelial progenitors from human adipose tissue," Biomaterials, vol. 32, no. 25, pp. 5801-5809, 2011.

[67] A. M. Müller, A. Mehrkens, D. J. Schäfer et al., "Towards an intraoperative engineering of osteogenic and vasculogenic grafts from the stromal vascular fraction of human adipose tissue," European Cells and Materials, vol. 19, pp. 127-135, 2010.

[68] P.-P. A. Vergroesen, R.-J. Kroeze, M. N. Helder, and T. H. Smit, "The use of poly(L-lactide-co-caprolactone) as a scaffold for adipose stem cells in bone tissue engineering: application in a spinal fusion model," Macromolecular Bioscience, vol. 11, no. 6, pp. 722-730, 2011.

[69] M. Dominici, K. Le Blanc, I. Mueller et al., "Minimal criteria for defining multipotent mesenchymal stromal cells. The International Society for Cellular Therapy position statement," Cytotherapy, vol. 8, no. 4, pp. 315-317, 2006.

[70] E. Cukierman, R. Pankov, D. R. Stevens, and K. M. Yamada, "Taking cell-matrix adhesions to the third dimension," Science, vol. 294, no. 5547, pp. 1708-1712, 2001.

[71] A. Banfi, A. Muraglia, B. Dozin, M. Mastrogiacomo, R. Cancedda, and R. Quarto, "Proliferation kinetics and differentiation potential of ex vivo expanded human bone marrow stromal cells: implications for their use in cell therapy," Experimental Hematology, vol. 28, no. 6, pp. 707-715, 2000. 
[72] A. Braccini, D. Wendt, C. Jaquiery et al., "Three-dimensional perfusion culture of human bone marrow cells and generation of osteoinductive grafts," STEM CELLS, vol. 23, no. 8, pp. 10661072, 2005.

[73] A. Abbott, "Cell culture: biology's new dimension," Nature, vol. 424, no. 6951, pp. 870-872, 2003.

[74] A. M. Phillips, "Overview of the fracture healing cascade," Injury, vol. 36, supplement 3, pp. S5-S7, 2005.

[75] K. Shao, C. Koch, M. K. Gupta et al., "Induced pluripotent mesenchymal stromal cell clones retain donor-derived differences in DNA methylation profiles," Molecular Therapy, vol. 21, no. 1, pp. 240-250, 2013.

[76] A. Dellavalle, M. Sampaolesi, R. Tonlorenzi et al., "Pericytes of human skeletal muscle are myogenic precursors distinct from satellite cells," Nature Cell Biology, vol. 9, no. 3, pp. 255-267, 2007.

[77] T. Vinardell, E. J. Sheehy, C. T. Buckley, and D. J. Kelly, "A comparison of the functionality and in vivo phenotypic stability of cartilaginous tissues engineered from different stem cell sources," Tissue Engineering Part A, vol. 18, no. 11-12, pp. 11611170, 2012.

[78] A. Reinisch, N. Etchart, D. Thomas et al., "Epigenetic and in vivo comparison of diverse MSC sources reveals an endochondral signature for human hematopoietic niche formation," Blood, vol. 125, no. 2, pp. 249-260, 2015.

[79] A. M. Craft, J. S. Rockel, Y. Nartiss, R. A. Kandel, B. A. Alman, and G. M. Keller, "Generation of articular chondrocytes from human pluripotent stem cells," Nature Biotechnology, vol. 33, no. 6, pp. 638-645, 2015.

[80] H. Busser, M. Najar, G. Raicevic et al., "Isolation and characterization of human mesenchymal stromal cell subpopulations: comparison of bone marrow and adipose tissue," Stem Cells and Development, vol. 24, no. 18, pp. 2142-2157, 2015.

[81] P. Bianco and P. G. Robey, "Skeletal stem cells," Development, vol. 142, pp. 1023-1027, 2015.

[82] A. I. Caplan, "What's in a name?" Tissue Engineering Part A, vol. 16, no. 8, pp. 2415-2417, 2010.

[83] C. K. F. Chan, E. Y. Seo, J. Y. Chen et al., "Identification and specification of the mouse skeletal stem cell," Cell, vol. 160, no. 1-2, pp. 285-298, 2015.

[84] C. Scotti, E. Piccinini, H. Takizawa et al., "Engineering of a functional bone organ through endochondral ossification," Proceedings of the National Academy of Sciences of the United States of America, vol. 110, no. 10, pp. 3997-4002, 2013.

[85] J. I. Huang, N. Kazmi, M. M. Durbhakula, T. M. Hering, J. U. Yoo, and B. Johnstone, "Chondrogenic potential of progenitor cells derived from human bone marrow and adipose tissue: a patient-matched comparison," Journal of Orthopaedic Research, vol. 23, no. 6, pp. 1383-1389, 2005.

[86] P. G. Robey, "Cell sources for bone regeneration: the good, the bad, and the ugly (but promising)," Tissue Engineering B: Reviews, vol. 17, no. 6, pp. 423-430, 2011.

[87] M. N. Helder, M. Knippenberg, J. Klein-Nulend, and P. I. J. M. Wuisman, "Stem cells from adipose tissue allow challenging new concepts for regenerative medicine," Tissue Engineering, vol. 13, no. 8, pp. 1799-1808, 2007.

[88] F. Z. Asumda and P. B. Chase, "Age-related changes in rat bonemarrow mesenchymal stem cell plasticity," BMC Cell Biology, vol. 12, article 44, 2011.

[89] G. V. Røsland, A. Svendsen, A. Torsvik et al., "Long-term cultures of bone marrow-derived human mesenchymal stem cells frequently undergo spontaneous malignant transformation," Cancer Research, vol. 69, no. 13, pp. 5331-5339, 2009.
[90] D. E. Ingber, V. C. Mow, D. Butler et al., “Tissue engineering and developmental biology: going biomimetic," Tissue Engineering, vol. 12, no. 12, pp. 3265-3283, 2006.

[91] E. J. Sheehy, T. Vinardell, C. T. Buckley, and D. J. Kelly, "Engineering osteochondral constructs through spatial regulation of endochondral ossification," Acta Biomaterialia, vol. 9, no. 3, pp. 5484-5492, 2013.

[92] P. T. Sharpe and C. S. Young, "Test-tube teeth," Scientific American, vol. 293, no. 2, pp. 34-41, 2005.

[93] M. G. Haugh, E. G. Meyer, S. D. Thorpe, T. Vinardell, G. P. Duffy, and D. J. Kelly, "Temporal and spatial changes in cartilagematrix-specific gene expression in mesenchymal stem cells in response to dynamic compression," Tissue Engineering Part A, vol. 17, no. 23-24, pp. 3085-3093, 2011.

[94] W. Hoffmann, S. Feliciano, I. Martin, M. de Wild, and D. Wendt, "Novel perfused compression bioreactor system as an in vitro model to investigate fracture healing," Frontiers in Bioengineering and Biotechnology, vol. 3, article 10, 2015.

[95] A. J. Steward, S. D. Thorpe, T. Vinardell, C. T. Buckley, D. R. Wagner, and D. J. Kelly, "Cell-matrix interactions regulate mesenchymal stem cell response to hydrostatic pressure," Acta Biomaterialia, vol. 8, no. 6, pp. 2153-2159, 2012.

[96] P. Janicki, P. Kasten, K. Kleinschmidt, R. Luginbuehl, and W. Richter, "Chondrogenic pre-induction of human mesenchymal stem cells on $\beta$-TCP: enhanced bone quality by endochondral heterotopic bone formation," Acta Biomaterialia, vol. 6, no. 8, pp. 3292-3301, 2010.

[97] K. A. D’Amour, A. G. Bang, S. Eliazer et al., "Production of pancreatic hormone-expressing endocrine cells from human embryonic stem cells," Nature Biotechnology, vol. 24, no. 11, pp. 1392-1401, 2006.

[98] S. J. Liebowitz and S. E. Margolis, "Path dependence, lock-in, and history," The Journal of Law, Economics, \& Organization, vol. 11, no. 1, pp. 205-226, 1995, http://jleo.oxfordjournals.org/ content/11/1/205.full.pdf.

[99] S. Stegen, N. van Gastel, and G. Carmeliet, "Bringing new life to damaged bone: the importance of angiogenesis in bone repair and regeneration," Bone, vol. 70, pp. 19-27, 2015.

[100] M. Ogawa, M. Oshima, A. Imamura et al., "Functional salivary gland regeneration by transplantation of a bioengineered organ germ," Nature Communications, vol. 4, 2013.

[101] E. J. Sheehy, T. Vinardell, M. E. Toner, C. T. Buckley, and D. J. Kelly, "Altering the architecture of tissue engineered hypertrophic cartilaginous grafts facilitates vascularisation and accelerates mineralisation," PLoS ONE, vol. 9, no. 3, Article ID e90716, 2014.

[102] J. M. Jukes, S. K. Both, A. Leusink, L. M. T. Sterk, C. A. Van Blitterswijk, and J. de Boer, "Endochondral bone tissue engineering using embryonic stem cells," Proceedings of the National Academy of Sciences of the United States of America, vol. 105, no. 19, pp. 6840-6845, 2008.

[103] H. M. Kronenberg, "Developmental regulation of the growth plate," Nature, vol. 423, no. 6937, pp. 332-336, 2003.

[104] L. C. Gerstenfeld, D. M. Cullinane, G. L. Barnes, D. T. Graves, and T. A. Einhorn, "Fracture healing as a post-natal developmental process: molecular, spatial, and temporal aspects of its regulation," Journal of Cellular Biochemistry, vol. 88, no. 5, pp. 873-884, 2003.

[105] A. Vortkamp, S. Pathi, G. M. Peretti, E. M. Caruso, D. J. Zaleske, and C. J. Tabin, "Recapitulation of signals regulating embryonic bone formation during postnatal growth and in fracture repair," Mechanisms of Development, vol. 71, no. 1-2, pp. 65-76, 1998. 
[106] B. K. Hall and T. Miyake, "All for one and one for all: condensations and the initiation of skeletal development," BioEssays, vol. 22, no. 2, pp. 138-147, 2000.

[107] L. C. Gerstenfeld, J. Cruceta, C. M. Shea, K. Sampath, G. L. Barnes, and T. A. Einhorn, "Chondrocytes provide morphogenic signals that selectively induce osteogenic differentiation of mesenchymal stem cells," Journal of Bone and Mineral Research, vol. 17, no. 2, pp. 221-230, 2002.

[108] K. Nakao, R. Morita, Y. Saji et al., "The development of a bioengineered organ germ method," Nature Methods, vol. 4, no. 3, pp. 227-230, 2007.

[109] H.-P. Gerber, T. H. Vu, A. M. Ryan, J. Kowalski, Z. Werb, and N. Ferrara, "VEGF couples hypertrophic cartilage remodeling, ossification and angiogenesis during endochondral bone formation," Nature Medicine, vol. 5, no. 6, pp. 623-628, 1999.

[110] I. Martin, "Engineered tissues as customized organ germs," Tissue Engineering Part: A, vol. 20, no. 7-8, pp. 1132-1133, 2014.

[111] M. Mumme, C. Scotti, A. Papadimitropoulos et al., "Interleukin- $1 \beta$ modulates endochondral ossification by human adult bone marrow stromal cells," European Cells and Materials, vol. 24, pp. 224-236, 2012.

[112] J. Yang, M. Yamato, T. Shimizu et al., "Reconstruction of functional tissues with cell sheet engineering," Biomaterials, vol. 28, no. 34, pp. 5033-5043, 2007.

[113] T. A. Burd, M. S. Hughes, and J. O. Anglen, "Heterotopic ossification prophylaxis with indomethacin increases the risk of long-bone nonunion," The Journal of Bone and Joint SurgeryBritish Volume, vol. 85, no. 5, pp. 700-705, 2003.

[114] J. Ding, O. Ghali, P. Lencel et al., "TNF- $\alpha$ and IL-1 $\beta$ inhibit RUNX2 and collagen expression but increase alkaline phosphatase activity and mineralization in human mesenchymal stem cells," Life Sciences, vol. 84, no. 15-16, pp. 499-504, 2009.

[115] M. Liebergall, J. Schroeder, R. Mosheiff et al., "Stem cell-based therapy for prevention of delayed fracture union: a randomized and prospective preliminary study," Molecular Therapy, vol. 21, no. 8, pp. 1631-1638, 2013.

[116] D. Dallari, L. Savarino, C. Stagni et al., "Enhanced tibial osteotomy healing with use of bone grafts supplemented with platelet gel or platelet gel and bone marrow stromal cells," The Journal of Bone \& Joint Surgery-American Volume, vol. 89, no. 11, pp. 2413-2420, 2007.

[117] P. Hernigou, G. Mathieu, A. Poignard, O. Manicom, F. Beaujean, and H. Rouard, "Percutaneous autologous bone-marrow grafting for nonunions. Surgical technique," The Journal of Bone and Joint Surgery-American Volume, vol. 88, supplement 1, part 2, pp. 322-327, 2006.

[118] S. F. Badylak, D. J. Weiss, A. Caplan, and P. MacChiarini, "Engineered whole organs and complex tissues," The Lancet, vol. 379, no. 9819, pp. 943-952, 2012.

[119] D. J. Wainwright, "Use of an acellular allograft dermal matrix (AlloDerm) in the management of full-thickness burns," Burns, vol. 21, no. 4, pp. 243-248, 1995.

[120] M. E. Franklin Jr., J. M. Treviño, G. Portillo, I. Vela, J. L. Glass, and J. J. González, "The use of porcine small intestinal submucosa as a prosthetic material for laparoscopic hernia repair in infected and potentially contaminated fields: longterm follow-up," Surgical Endoscopy and Other Interventional Techniques, vol. 22, no. 9, pp. 1941-1946, 2008.

[121] S. M. Irvine, J. Cayzer, E. M. Todd et al., "Quantification of in vitro and in vivo angiogenesis stimulated by ovine forestomach matrix biomaterial," Biomaterials, vol. 32, no. 27, pp. 6351-6361, 2011.
[122] S. Lun, S. M. Irvine, K. D. Johnson et al., "A functional extracellular matrix biomaterial derived from ovine forestomach," Biomaterials, vol. 31, no. 16, pp. 4517-4529, 2010.

[123] R. G. Will, "Epidemiology of Creutzfeldt-Jakob disease," British Medical Bulletin, vol. 49, no. 4, pp. 960-970, 1993.

[124] T. J. Keane, I. T. Swinehart, and S. F. Badylak, "Methods of tissue decellularization used for preparation of biologic scaffolds and in vivo relevance," Methods, vol. 84, pp. 25-34, 2015.

[125] D. C. Logan, "Known knowns, known unknowns, unknown unknowns and the propagation of scientific enquiry," Journal of Experimental Botany, vol. 60, no. 3, pp. 712-714, 2009. 

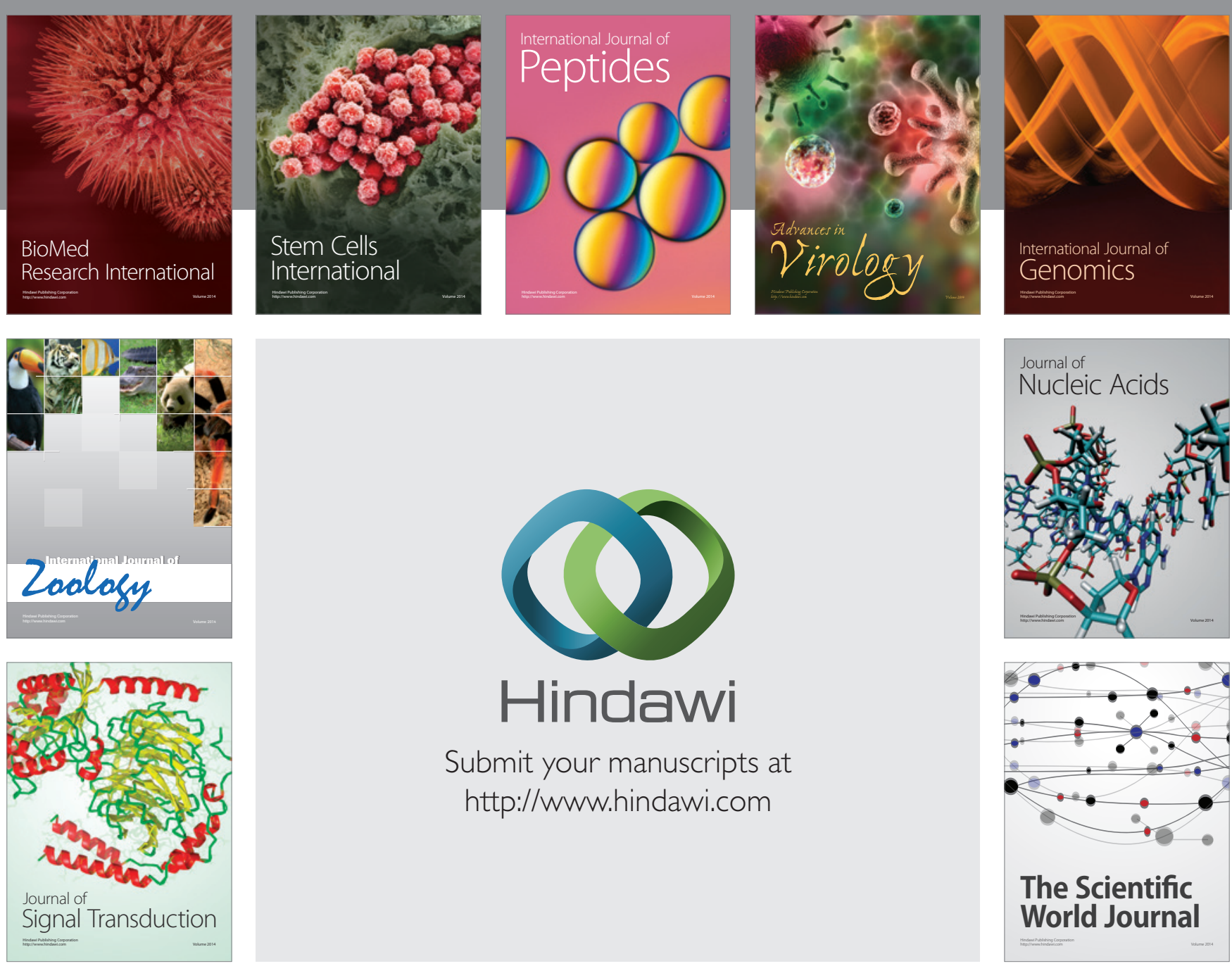

Submit your manuscripts at

http://www.hindawi.com
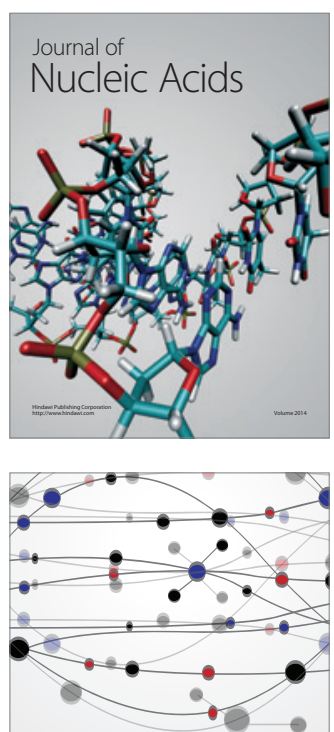

The Scientific World Journal
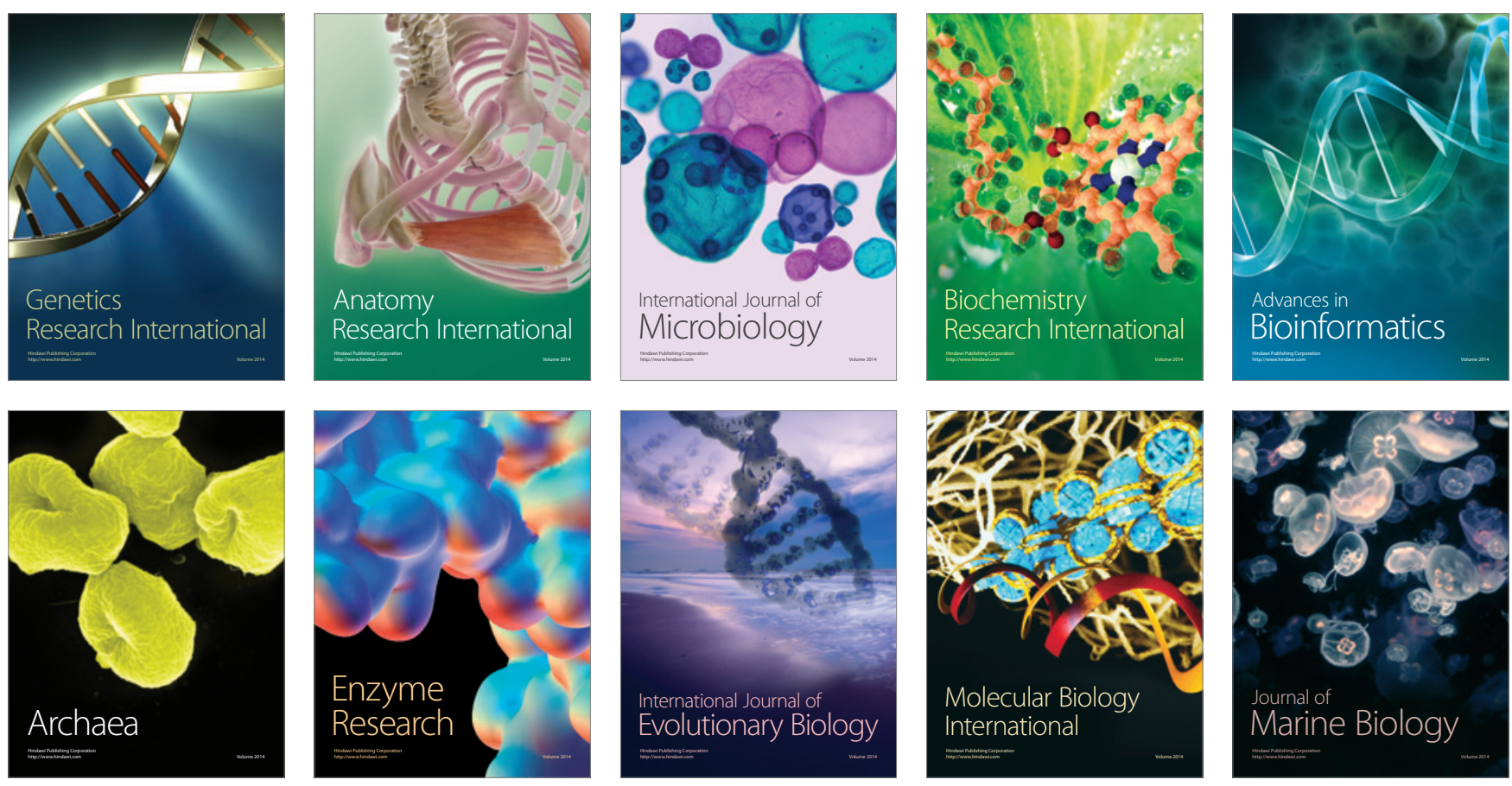